\title{
LAS INVESTIGACIONES EN EL FUERTE BLANCA GRANDE
}

\author{
Julio Fabián Merlo ${ }^{1}$ y Luisina Merlo²
}

Recibido: 10 de marzo de 2018. Aceptado: 23 de septiembre de 2018

\begin{abstract}
Resumen
En este trabajo se presenta una sintesis de la documentación generada a lo largo de los años en la zona de la Laguna Blanca Grande, que van desde los trabajos realizados por Bórmida, en los que describe y define al Blancagrandense como una industria lítica que surge en el 3500 a.C. y perdura hasta momentos históricos, sin hacer ninguna mención del Fuerte Blanca Grande. El fuerte es luego resaltado por los historiadores locales Arena, Valverde y Cortez, y retomado en los trabajos de Goñi y Madrid y del historiador local Paladino. Estos trabajos han sido continuados por nuestro análisis documental y arqueológico, este último efectuado en el sector noroeste y la parte posterior del fuerte, y la laguna. Desde mediados del siglo $\mathrm{XX}$ se generaron investigaciones de diferentes campos disciplinarios que nunca se cruzaron entre sí, ocultando o negando la continuidad del registro arqueológico, que refleja tanto las ocupaciones pre como postconquista de la región pampeana. En este trabajo se plantea que separar la arqueología en pre y postconquista restringe el conocimiento de nuestro pasado, estableciendo una división artificial en la arqueología pampeana.
\end{abstract}

Palabras clave: pre y postconquista, Laguna Blanca Grande, Blancagrandense, Fuerte Blanca Grande, frontera, siglo XIX

\begin{abstract}
This paper presents a synthesis of the information generated over the years in the area of the Laguna Blanca Grande, starting with the work carried out by Bórmida, in which he described and defined the Blancagrandense as a lithic industry that arose around 3500 b.C. and lasted until historical times, without mentioning the Fort Blanca Grande. The fort was highlighted by the local historians Arena, Valverde and Cortez, and later by the works by Goñi and Madrid, and the local historian Paladino. Studies on the fort have been continued by the documentary and archaeological analyses carried out in the northwestern sector, the back part of the fort and the lagoon. Since the mid-twentieth century, research has been generated from different interdisciplinary fields that never touched on each other, hiding or denying the continuity in the archaeological record, which reflects the pre- and post-conquest occupations of the Pampaean region. In this work it is argued that separating archeology in pre- and post-conquest periods restricts the knowledge of our past, establishing an artificial division in Pampaean archeology.
\end{abstract}

Key Words: Fort Blanca Grande, Camino de los Indios a Salinas, frontier, XIX ${ }^{\text {th }}$ century, archaeofaunal remains

1 INCUAPA CONICET-UNICEN, Facultad de Ciencias Sociales. Olavarría, Av. Del Valle 5737, (B7400WI) Olavarria, Buenos Aires; E-mail: jmerlo@soc.unicen.edu.ar

2 Facultad de Ciencias Sociales. Olavarría-UNICEN, Av. Del Valle 5737, (B 7400 WI) Olavarría, Buenos Aires. E-mail: luisinamerlo21@gmail.com 


\section{Introducción}

En este trabajo se realiza una sintesis del estado actual del conocimiento arqueológico de las sociedades de frontera de la región pampeana, focalizando en las investigaciones que se desarrollaron en el Fuerte Blanca Grande (FGB). Este sitio posee registros documentales y de cultura material de ocupaciones pre y postconquista hasta el siglo XIX. Los datos recopilados hasta el momento han sido generados por diferentes miradas que involucran distintas disciplinas. Estos estudios incluyen trabajos informales, concebidos por entusiastas, lugareños, historiadores aficionados, entre otros, y plasmados de forma heterogénea, hecho que dificulta la construcción de un panorama sistemático y representativo. También desde lo académico y especialmente desde las investigaciones que efectuó Bórmida en la década de 1960, donde define el Blancagrandense y el Bolivarense. Este trabajo busca recopilar un corpus empírico riguroso que enriquezca o esclarezca los datos aportados por aquellas personas que, por rescatar las historias o la arqueología del lugar, resaltaron o invicibilizaron algunos de estos registros (arqueológicos y documentales).

El FBG, se ubica en el sector noroeste del Partido de Olavarría a orillas de la laguna homónima, a $36^{\circ} 29^{\prime} 27.84^{\prime \prime}$ de Latitud Sur y $60^{\circ}$ 53' 39.12" de Longitud Oeste. Este fuerte tiene una extensión aproximada de $500 \mathrm{~m}$ por $200 \mathrm{~m}$, está rodeado por un foso perimetral y posee dos estructuras secundarias, de forma triangular en sus laterales (Merlo 1999, 2014). El área central y las estructuras laterales se pueden definir por la presencia de fosas que dan a conocer el perímetro del fuerte. En los vértices que unen el lado sur (frente del fuerte) se puede observar dos montículos, correspondientes a antiguos baluartes, de $4 \mathrm{~m}$ de altura aproximadamente (Langiano y Merlo 2013). El sector noroeste (parte posterior del fuerte) limita con la Laguna Blanca Grande.

Desde la década de 1950 se han efectuado investigaciones arqueológicas en la zona de la Laguna Blanca Grande, iniciadas por Bórmida (1960), pero es recién a partir de 1990 cuando comenzaron a realizarse trabajos sistemáticos de investigación sobre el período postconquista, integrando en el análisis diferentes miradas como la arqueología, historia, etnohistoria, cartografia, geología y antropología. En este marco, por ejemplo, se ha generado conocimiento sobre el empleo de estrategias y recursos faunísticos que implementaron los primeros pobladores hispanocriollos y los posteriores eurocriollos (Merlo 2014). Estos grupos interactuaron con los pueblos originarios que ocuparon la región pampeana, desde los contactos tempranos hasta la formación de los primeros pueblos y la expulsión de las tribus que ofrecian resistencia a las autoridades militares del estado.

Una revisión exhaustiva de cada una de las investigaciones realizadas por los diferentes autores excedería los objetivos de este trabajo. Se sintetizan los postulados e hipótesis que enfatizan los aspectos relacionados con la interacción y la forma de vida de las sociedades de frontera, y cómo éstas fueron modificándose a medida que se incrementaba la población extranjera (inmigrantes europeos, de diferentes sectores del país y de América) al sur del río Salado. Posteriormente, se efectúa una síntesis de los últimos resultados de los trabajos en el sector noroeste del FBG. Estas investigaciones contribuyen a conformar un corpus de información que enriquece el conocimiento sobre las sociedades que ocuparon el interior de la provincia de Buenos Aires (originaria y eurocriolla) y como interactuaron entre sí, durante gran parte del siglo XIX. 


\section{El desarrollo de la Arqueología Histórica en la Provincia de Buenos Aires}

Las investigaciones en arqueología de momentos históricos en la Provincia de Buenos Aires comenzaron a desarrollarse con mayor énfasis a principios de la década de 1990. Bárcena y Schávelzon (1990) emprendieron trabajos en contextos urbanos, excavando sitios que representan los diferentes períodos de ocupación de la ciudad de Buenos Aires y logrando, en muchos de los casos, rescatar y proteger el patrimonio arqueológico y arquitectónico al norte del río Salado. En el interior de la región pampeana, Madrid (1991) realizó estudios arqueológicos de los sitios con estructuras de piedra (Sierra de Pillahuinco, Sistema de Ventania) con el objeto de conocer los modos de subsistencia, asentamiento, tecnología y organización de los grupos indigenas de las sierras bonaerenses durante el Holoceno Tardio y el período de contacto Hispano-Indígena, y cómo fue el aprovechamiento de las espe- cies introducidas (Madrid 1991). Por otro lado, Sempé, junto a Pérez Meroni y Paleo, están llevando a cabo prospecciones y excavaciones en Punta Indio, Provincia de Buenos Aires desde 1990 (Sempé et al. 1991). Sus investigaciones sobre sitios de ocupación indígena en tiempos históricos están focalizadas en el Área Norte de la subregión Pampa Húmeda. La propuesta metodológica utilizada propone diferentes vías de análisis y en especial el estudio de fuentes históricas (hispanas) de la época de contacto.

En 1992, Goñi y Madrid (1998), por iniciativa de la Comisión Municipal de Estudios Históricos de Olavarría, elaboraron el proyecto Fuerte Blanca Grande y comenzaron a realizar trabajos de campo en el lugar, con financiación municipal (Figura 1). Los autores emplearon el modelo económico de Cashdan (1990) de riesgo e incertidumbre para interpretar las sociedades cazadoras recolectoras, planteando que las variaciones en las condiciones ambientales y económicas producen situaciones de riesgo y la falta de información

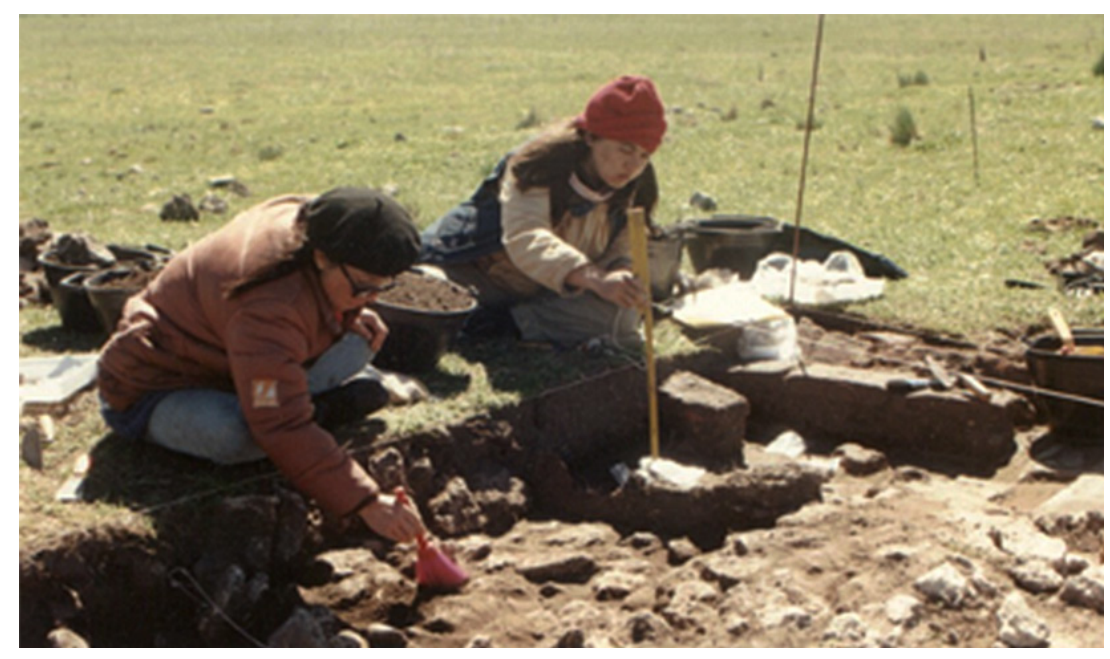

Figura 1. Excavación realizada en 1994, en el sector denominado Puesto Viejo del FBG. Las participantes de la excavación, Patricia Madrid (izquierda) y Marta Roa (derecha). 
produce incertidumbre (Cashdan 1990:1, ver discusión en Merlo 2014). En el proyecto del FBG participaron alumnos de la Facultad de Ciencias Sociales de Olavarría de la UNICEN y se generaron varias tesis de licenciatura, que abordan diferentes temáticas.

Contemporáneamente, Gómez Romero y Ramos (1994) comenzaron la investigación arqueológica de un sitio fortificado de Azul, el Fortín Miñana, un asentamiento militar de la frontera del Sur ocupado durante la década de 1860. Los autores analizaron la evidencia material y sus relaciones a nivel estratigráfico en lo que constituye un piso de ocupación.

En 1997, Ormazábal, Langiano y Merlo iniciaron el estudio de un complejo sistema de relación interétnica asimétrica en la Frontera del Sur bonaerense durante la segunda mitad del siglo XIX, por medio del análisis de una serie de puestos fortificados (Fortín Fe, La Parva, El Perdido, Fuerte Lavalle y San Martín) articulados en torno al denominado "Camino de los Indios a Salinas", en el área Interserrana bonaerense (Figura 3). Los autores plantearon un marco regional de alta fricción en la zona fronteriza, con una movilidad ofensiva de avanzada de doscientos kilómetros entre 1858 y 1876, concretando una investigación de tipo regional, holística y con una perspectiva antropológica que se continúa hasta la actualidad. En el marco de esta investigación, se establecieron convenios con los municipios donde se ubicaban los sitios arqueológicos (Fortín La Parva y Fuerte Esperanza en General Alvear; Localidad Arqueológica El Perdido, Fortín Arroyo Corto, Fuerte Lavalle y FBG en Olavarria; Fuerte Independencia en Tandil; y Fuerte San Martín en Coronel Suárez) con la finalidad de transmitir a las comunidades locales las investigaciones y conocimientos logrados (Langiano et al. 1997, 2002). En estos lugares se realizaron diversos análisis del material recuperado y estudios de la fauna y de la cultura material presente en dichos sitios (Langiano et al. 1997). Dichos convenios y trabajos arqueológicos se continúan en la actualidad. Mugueta y Guerci efectuaron en 1997 un convenio similar con la Municipalidad de Tapalqué para realizar investigaciones arqueológicas en el sitio Cantón Tapalqué Viejo, que generó una serie de trabajos que analizaron diferentes aspectos de ese asentamiento fortificado fundado en 1831 (Mugueta y Guerci 1997).

Recapitulando, en las investigaciones arqueológicas de momentos históricos 1levadas a cabo en las últimas décadas se ha avanzado tanto en aspectos teóricos como metodológicos, discutiendo conceptos y desarrollando métodos de análisis sobre loza, metales y vidrios, entre otros materiales de procedencia hispanocriolla y europea, indagando en su procedencia, ubicación cronológica, etc.; incluso en algunos casos, se han propuesto secuencias tipológicas. Sin embargo, aún hay falencias en los estudios realizados sobre arqueofauna de momentos históricos, aunque existe una tendencia creciente a su desarrollo como se señalará a continuación.

Mario Silveira realizó las primeras investigaciones sobre arqueofaunas de momentos históricos. En 1995, analizó restos óseos obtenidos en la excavación de la casa de una familia patricia, los Peña, que vivieron a fines del siglo XIX en la esquina de las calles San Lorenzo y Defensa (Barrio de San Telmo) en la ciudad de Buenos Aires; las tareas de excavación arqueológica estuvieron bajo la dirección de Schávelzon y Zarankin (Silveira 1995). Silveira también realizó investigaciones en la Laguna El Trompa (Silveira 1992), en sitios a cielo abierto correspondientes a grupos indigenas de la llanura Interserrana bonaerense, planteando la coexistencia de la fauna de origen doméstico con el guanaco.

El surgimiento de manera sistemática de las investigaciones en arqueología post- 
conquista repercutió en el incremento de trabajos sobre asentamientos fortificados del siglo XIX de la Provincia de Buenos Aires. Para fines de la década de 1990 y principios del 2000, hubo un notable desarro1lo de investigaciones de sitios de frontera. Se profundizaron los trabajos en varios de los sitios anteriormente mencionados y se incorporaron otros, generándose un mayor número de investigadores nucleados en torno a la arqueología postcontacto (Figura 2). Esto se refleja en el volumen de trabajos sobre temas específicos de interés en la arqueología de momentos históricos regionales (i.e. Brittez 2000, 2009; Brittez y Wibaux 2011; Casanueva 2004; Gómez Ro-

Figura 2. Mapa con la localización de algunos de los sitios arqueológicos de frontera citados en esta tesis. Referencias: 1) Fuerte Independencia, 2) FBG, 3) Fortín La Parva 4) Fortín Miñana, 5) Fortín El Perdido, 6) Fuerte San Quilcó o Lavalle, 7) Arroyo Nieves, 8) Fortín arroyo Corto, 9) Fuerte General Paz, 10) Fortín Olavarria y 11) Fortín Otamendi.

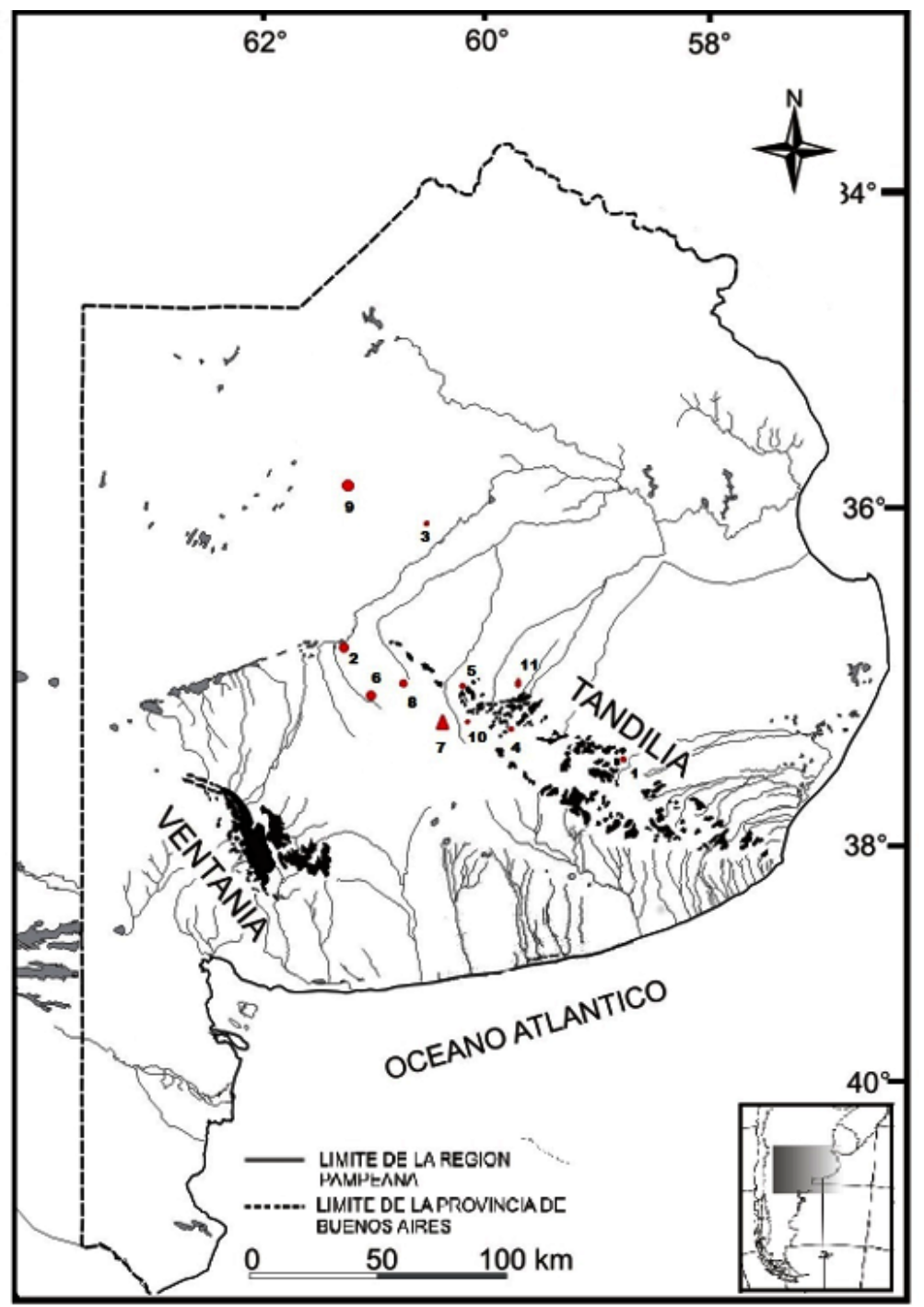


mero 1997, entre otros; Landa et al. 2011; Langiano 2007; Langiano y Merlo 2013; Langiano et al. 2002, 2006, 2009; Leoni et al. 2006, 2007, 2008a, 2008b, 2010; Merlo 2003, 2004, 2007; Merlo y Moro 2004; Mugueta Guerci 2012; Pedrotta 2005; Pedrotta y Bagaloni 2005, 2011; Pedrotta et al. 2011; Ramos et al. 2008; entre otros). Este crecimiento ha generado que se realicen encuentros regionales, provinciales y nacionales que involucran a investigadores con limites temporales acotados y problemáticas específicas. A pesar de este crecimiento, aún no se ha logrado el desarrollo de encuentros específicos de temas afines (como la zooarqueología de momentos históricos o el uso de elementos vítreos en arqueología histórica), aunque sí es notable el desarrollo de mesas temáticas dentro de los encuentros nacionales y regionales de arqueología general y arqueología histórica.

El incremento de trabajos de investigación que se produjo a partir de la década del 2000 ha generado un crecimiento notable del conocimiento sobre las sociedades postcontacto, y principalmente de la arqueología de frontera y/o la arqueología del conflicto, poniendo a la luz historias e interpretaciones que enriquecen el conocimiento del pasado regional. Pero por otro lado, se ha generado una marcada brecha entre las investigaciones arqueológicas pre- y postconquista, donde los arqueólogos que investigan sitios cazadores recolectores ignoran los artefactos o vestigios que dan indicios del contacto, o simplemente los mencionan sin ninguna preocupación de indagar más sobre el tema, o los atribuyen a procesos postdepositacionales, ignorando la continuidad de lo ocurrido. En este punto es importante la contribución de la etnohistoria, que mediante el análisis de documentos, cartografia y fotografias del siglo XIX muestra la interacción de las diferentes sociedades.

\section{Las primeras investigaciones sobre ocupaciones fortificadas}

Las primeras indagaciones acerca de las sociedades de frontera fueron realizadas por historiadores y, en muchos de los casos, por investigadores autodidactas que, a partir de documentos de archivos y relatos, anécdotas de la memoria oral de antiguos pobladores y algún que otro vestigio arquitectónico o arqueológico, generaron conocimientos históricos. Si bien la mayoría de estos aportes presenta diversas falencias, muchos de ellos son verdaderos disparadores de hipótesis e ideas que generan la necesidad de investigar, corroborar o aclarar científicamente los datos aportados.

Luego de establecerse las primeras fortificaciones en territorios que pertenecian a pueblos originarios, comenzaron a radicarse los primeros colonos que se dedicaban a la producción y al comercio mediante las pulperías o a la actividad ganadera en la campaña bonaerense. Este nuevo territorio comenzó a ser recorrido progresivamente por científicos, eclesiásticos, médicos, comerciantes, militares, vagabundos, desertores del ejército y de la ley; muchos de estos nuevos ocupantes provenian de Europa, desplazados de sus países de origen. En ese período se facilitó la apropiación de tierras de las comunidades originarias, que pasaron a un reducido grupo de elite de ascendencia europea o a militares en pago por sus servicios en la conquista de estas tierras. Esta oligarquía terrateniente junto con el gobierno, de características conservadoras en lo político y liberales en lo económico, incorporó a inmigrantes eurocriollos como mano de obra de bajo costo, para que trabajen la tierra, pero sin la posibilidad de ser dueños. Esta masa obrera que ingreso a la zona de frontera, se incrementó después de la "campaña al desierto". Los inmigrantes rurales, tratados de igual manera que las comu- 
nidades originarias, trajeron consigo nuevas costumbres, diferentes entre sí, que se fueron amalgamando y modificando la sociedad de tierra adentro de una forma gradual. Progresivamente muchos de estos asentamientos fronterizos pasaron al olvido, absorbidos por los ejidos de pueblos rurales o sirviendo como simples cuarteles de parada para las expediciones militares que expulsaban a los pueblos originarios al otro lado del río Negro. De esta manera se logró el ocultamiento y la destrucción de toda manifestación cultural, social y económica que se gestaba en la zona rural, que se interpusiera a los intereses del gobierno liberal que se acentuó en la generación de 1880 (ver Rapoport 2000).

El trabajo autodidacta presentados por Arena, Cortés y Valverde (1967) en su Ensayo Histórico del Partido de Olavarria, sintetiza las investigaciones que venían realizando y expresa controversias en lo que compete a situación y denominación de la región bajo estudio. Con respecto a los pueblos originarios y al proceso de ocupación de sus tierras en la segunda mitad del siglo XIX, afirman:

\begin{abstract}
"Olavarría, emplazada en el centro geográfico de la Provincia de Buenos Aires, fue...avanzada hacia del desierto, en esa titánica lucha del blanco contra los primitivos habitantes de nuestras pampas. Sus tierras fueron testigo mudo de las correrias del indómito salvaje y escenarios de acontecimientos importantes, pero por una rara ironía quedaron durante muchísimos años en el más lamentable de los olvidos" (Arena et al. 1967:III).
\end{abstract}

Los autores recopilaron documentos oficiales que habian sido publicados previamente en revistas de difusión local y documentos privados inéditos. Como expresan en el prólogo del ensayo:

"No siempre es posible llegar a los documentos privados, sea por ignorar su existencia, por el egoísmo propio de sus dueños o por el completo desorden en que se encuentran; también, por indiferencia, mucha de esa documentación se ha convertido en simple mercaderia, facilitando de esa manera su éxodo hacia el extranjero" (Arena et al. 1967:II).

En este trabajo se describen los topónimos dejados por los pueblos originarios que vivian en el lugar y cómo éstos se fueron modificando dependiendo del autor que los transcribiera. Se describe la organización social de las sociedades "Araucanas" que habitaban la región pampeana, cómo se componía el Aillarehue, agrupación social suprema del pueblo araucano, cómo se denominaban las distintas autoridades de una parcialidad indigena, como el Apogulmen o Apotilmen (superior al lonco) y el Toqui, que era el jefe en los momentos de guerra. También se analiza la división por género del trabajo y diversas costumbres que caracterizaban a los pueblos originarios de la zona, inclusive hasta las primeras décadas del siglo XX: el desarrollo de los parlamentos, la construcción de las viviendas y como éstas fueron modificándose a medida que se incrementó la población criolla y europea. Es destacable el registro fotográfico acerca de las diferentes actividades que realizaban en los toldos y la vestimenta autóctona mezclada con el uso de prendas que provenían de la sociedad eurocriolla.

En capítulos posteriores, Arena y colaboradores describen cómo fue el avance de la frontera en el centro de la Provincia de Buenos Aires y en especial cómo surgió el pueblo de Olavarría. Al respecto, se transcribe una carta del Coronel Ignacio Rivas (militar conocedor de la zona) al Presidente de la República, Bartolomé Mitre, donde le manifiesta su interés en crear un pueblo en las nacientes del arroyo Tapalqué, incorporar a Catriel y su tribu a vivir como "la gente" y ampliar la frontera para la producción de ganado y cultivos: 
"Campamento en las Puntas del Tapalqué Diciembre 15 de 1864

Excmo. Señor Presidente de la República, Brigadier General D. Bartolomé Mire.

Mi querido señor Presidente y amigo:

El paraje es aparente para un pueblo, y si se consiguiera que el Gobierno provincial lo decretase, estoy cierto que antes de un año estaría poblado, por el interés de los magnificos campos que tiene, y aguadas permanentes; $y$ así encerraríamos a Catriel, de modo que sin sentirlo se reduciria a vivir como la gente (...) por que estoy a seis leguas a retaguardia de Catriel, (...) Ignacio RIVAS" (citado en Arena et al. 1967:231-232).

Luego, mencionan que las tribus catrieleras, ubicadas sobre el arroyo Nievas, aceptaron la situación que implicaba un avance de hecho sobre las tierras que entonces ocupaban y sólo pidieron que se regularizara la entrega de raciones, ya que se encontraban padeciendo toda clase de miserias. En efecto, estaba hablando del surgimiento del pueblo de Olavarría. En otra carta posterior enviada por Rivas a Mitre, agrega: "Creo que Catriel y sus indios se acostumbrarán a vernos a sus espaldas $y$ se conformarán." (Archivo del General Mitre, To XXIV, pp. 32-33, transcripto en Arena et al. 1967:232).

Arena et al. (1967) describen también cómo los pueblos originarios negociaron con los eurocriollos los conflictos que se sucedieron a lo largo del siglo XIX, frente a una política de colonización fluctuante que sumaba el flujo de inmigrantes, que tuvo una forma pausada hasta $1870 \mathrm{e}$ incrementándose notablemente luego. No obstante, algunos de los caciques y líderes indígenas que habitaron en la región pampeana se las ingeniaron para mantener su rol y apuntalar sus intereses económicos, sociales y políticos. También se detallan las actividades vinculadas con el poblamiento rural y las campañas militares en la pampa -con las situaciones de contacto cultural- que ponen en evidencia diversos hitos sociales en la Frontera al Sur del río Salado en la segunda mitad del siglo XIX y se analizan una serie de puestos fortificados en el área Interserana bonaerense.

Cabe recordar que en 1878 Julio A. Roca decidió poner en práctica la ley sancionada en 1867 que intentaba resolver el problema de la frontera interior, extendiendo la misma hasta los limites naturales de los ríos Negro y Neuquén. Cuando Roca asumió la primera magistratura del país se incrementó la guerra ofensiva del gobierno nacional contra los pueblos indigenas (1879 a 1885). Los fuertes y fortines dejaron de cumplir un rol de inclusión cultural forzada para pasar a cumplir la función de control policial y "parada" para las expediciones que partian desde Buenos Aires con destino a la llamada "Campaña al Desierto"; o bien fueron quedando en el olvido.

El ensayo de Arena y colaboradores se basa en el análisis de fuentes documentales, incluyendo documentos oficiales que no fueron citados con las normas editoriales actuales, proponiendo una mirada crítica sobre el avance de frontera y la forma en que se diezmó la población originaria (Arena et al. 1967). Asimismo, estos autores llevaron a cabo una serie de recolecciones superficiales de materiales indígenas y europeos (e.g. puntas de flecha, boleadoras, morteros, ladrillos sin cocinar, entre otros artefactos), así como tareas de excavación, con la metodología de la época, en zonas rurales del partido de Olavarría como la Laguna de Paragüil, la estancia Santa Clara y el FBG. En este último sitio exhumaron restos humanos en el sector identificado como cementerio.

En 1993 y a raíz del inicio de las investigaciones arqueológicas en el FBG por Goñi y Madrid (1998), Paladino (1994) recopiló diversos documentos inéditos y varios manuscritos -que habían sido analizados por 


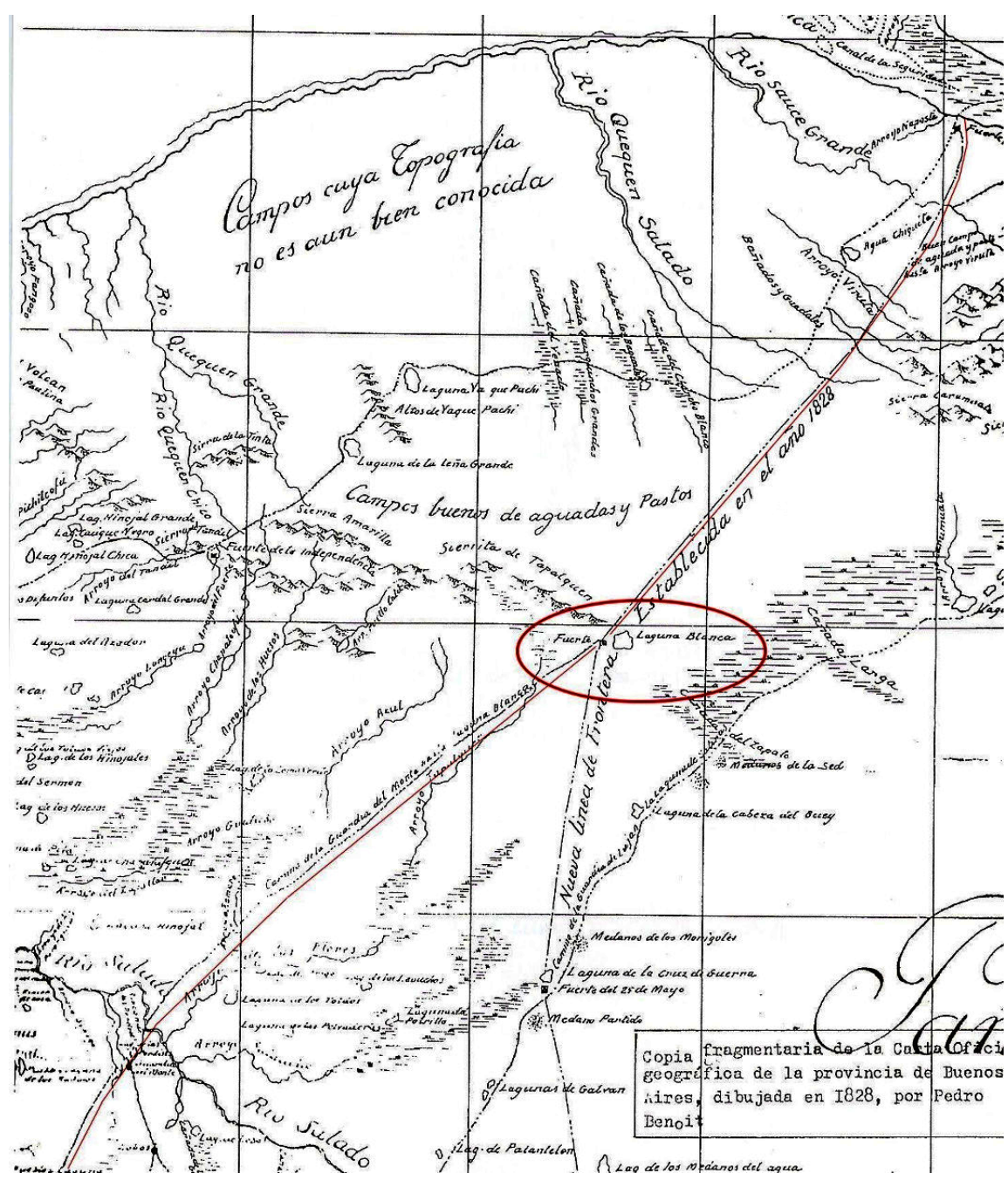

Figura 3. Copia de la Carta Oficial geográfica de la provincia de Buenos Aires dibujada en 1828 por Pedro Benoit, donde se puede observar el FBG y el Camino de la Guardia del Norte hacia Laguna Blanca Grande, posteriormente denominada Camino de los Indios a Salinas Grande o Camino de los Chilenos. El camino continúa con rumbo al río Salado pasando por el Arroyo Quilcó, donde en 1869 se construye el Fuerte Lavalle. Extraída del Manuscrito realizado por Alberto Valverde S/P (el resaltado en rojo es del autor).

Valverde- en el libro Tenemeche, editado por el Club de Pesca de Blanca Grande. Alli Paladino define las fechas de fundación del FBG, comenta los acontecimientos politi- cos que afectaron a la fortificación durante su fundación, el abandono por parte del gobierno, así como la reocupación del mismo y la venta de parte del fuerte a manos 
privadas, a principios del siglo $\mathrm{XX}$.

La mayoria de los historiadores aficionados y tradicionales no abordaron radicalmente las investigaciones sobre los pueblos originarios y las interacciones con el mundo eurocriollo. En algunos pocos casos, lo hicieron de forma somera, exacerbada o de manera xenofóbica (ver Botana 1977). Ciertamente, en los últimos años el desarrollo de la arqueología de momentos históricos y la etnohistoria ha avanzado en la temática, pero sigue siendo ajena al grueso de los historiadores que, frecuentemente, sólo se ocupan de ella de modo tangencial o, simplemente, la ignoran (ver comentarios en Mandrini 2007:20), en muchos casos ignorando el desarrollo de los trabajos de etnohistoriadores, antropólogos, arqueólogos e investigadores de otras disciplinas que se abocan a establecer un panorama de determinados procesos aportando información sobre las sociedades de frontera.

La casi inexistencia de investigaciones históricas sobre este tema hasta hace poco, dejó en manos de aficionados de diversas formaciones el rescate de la historia de los sucesos, acontecimientos y situaciones de la vida cotidiana del interior de campaña bonaerense. En estos abordajes puede encontrarse desde la exaltación de los valores de los soldados de frontera hasta la bravura de los pueblos originarios de estas tierras, que pasan de ser un desierto improductivo hostil y bárbaro a zonas fértiles de importante valor económico. Adicionalmente, la ausencia de trabajos multidisciplinarios con un eje centrado en la historia limitó ampliamente la generación de información sobre los asentamientos y pueblos del interior de la Provincia de Buenos Aires, en contraposición con las investigaciones arqueológicas que sin recelos incorporan y colocan en un mismo plano los datos históricos y arqueológicos sin perder la coherencia científica (ver Pedrotta y Gómez Romero 1998). La interacción de diferentes disciplinas como la historia, etnohistoria, antropología, arqueologia, geología, entre otras, aporta a la creación de un corpus de información que enriquecería el conocimiento del pasado regional.

\section{La Arqueologia pre y postcontacto en el área del FBG}

Los trabajos realizados por Menghín y Bórmida (1950) en Gruta del Oro y Margarita en el Sistema de Tandilia y el estudio comparativo con los materiales del sitio la Gruta del Ojo de Agua, dieron inicio a las investigaciones de sitios arqueológicos en el centro de la Provincia de Buenos Aires. Estos estudios fueron realizados bajo el paradigma Histórico-Cultural de origen austro-alemán, que se caracterizaba por explicar las variaciones de las industrias a través de la difusión, asignándoles a éstas distintos orígenes culturales. Teniendo en cuenta la posición estratigráfica y las comparaciones con los elementos recuperados en superficie, para la zona de Tandilia planteaban como hipótesis que "...existió alrededor del temprano postglacial una cultura muy primitiva, de morfología protolítica..." que "...se remonta hasta el tardiglacial...” y “...floreció durante el periodo del clima atlántico post-glacial alrededor del VI y $V$ milenio a. de J.C (....) sobreviviente en tiempos mucho más tardios que los de su formación originaria" (Menghin y Bórmida 1950:34). Esta cultura habría sido traída a América por "cazadores inferiores".

Posteriormente, Bórmida (1960) realizó entre 1958 y 1960 trabajos de campo en la zona de Olavarría y Bolivar, donde excavó cuatro yacimientos en bordes de las lagunas Cabeza de Buey, La Montura, Cubiló y Blanca Grande. También efectuó recolecciones superficiales en la playa de la laguna Blanca Grande, punto que se retomará más abajo. Estos estudios llevaron a Bórmida a definir dos industrias empa- 
rentadas con el Tandiliense, denominándolas Blancagrandense y Bolivarense, que se habrian iniciado en un período correlacionable con el suboreal entre los 3.500 años a.C. y el comienzo de la Era Cristiana. Estas industrias tenían características similares al Tandiliense, siendo la materia prima predominante la cuarcita, seguida por la calcedonia y en menor cantidad, el sílex. Desde el punto de vista tipológico, se caracterizaban por artefactos sobre lascas, unifaciales y marginales, a los que se les asociaban litos bifaciales, escasos porcentajes de retoque por presión y ausencia de cerámica (Bórmida 1960). Sanguinetti de Bórmida (1970, posteriormente, plantea que la pampa bonaerense podía ser considerada como un área con fisonomía propia que se hallaba caracterizada por una industria de cuarcita unifacial y marginal cuyo comienzo era el Tandiliense y se continuaba en el Blancagrandense, llegando en épocas muy recientes con la forma de un Bolivarense que se difundió por toda la región hasta perderse dentro de un contexto "neolitizado" y más tarde "araucanizado".

Merecen ser comentados con cierto detalle los trabajos arqueológicos realizados por Bórmida (1960) en la Laguna Blanca Grande, que consistieron en recolecciones de superficie y en la excavación de trincheras que, según Boschín (1991-1992), variaron entre 8 y $12 \mathrm{~m}^{2}$ y alcanzaron una profundidad entre $1,20 \mathrm{~m}$ y $2 \mathrm{~m}$. Los hallazgos en estratigrafia fueron escasos; la concentración mayor correspondió a una trinchera de $8 \mathrm{~m}^{2}$ y $1,50 \mathrm{~m}$ de profundi-

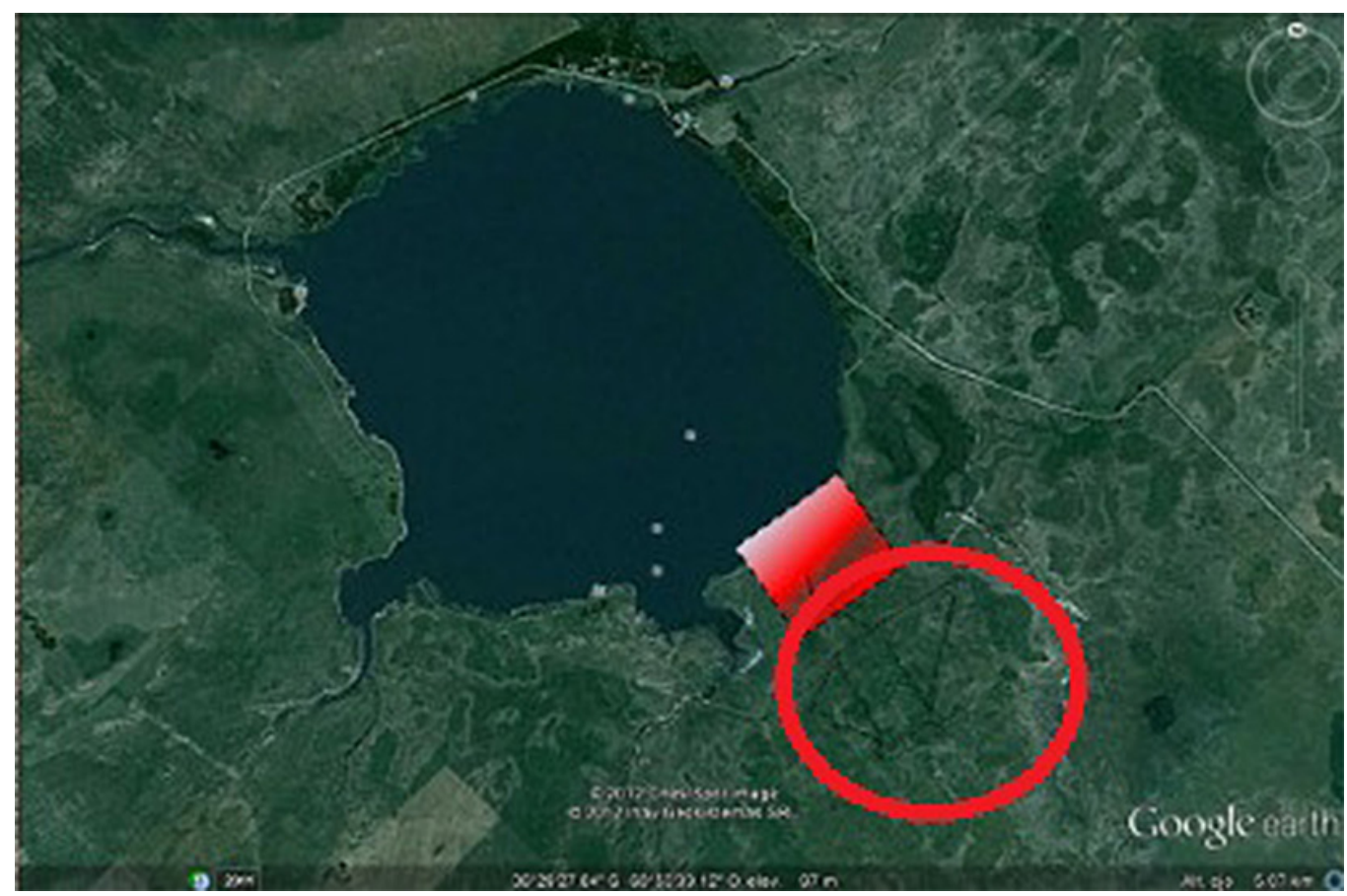

Figura 4. Localización de la zona posiblemente relevada por Bórmida en 1960 y el FBG (círculo rojo), relevado arqueológicamente desde 1992 hasta la actualidad. 
dad: 12 instrumentos líticos, 84 desechos líticos, tres fragmentos de cerámica y un trozo de pigmento mineral. En ningún momento se mencionó el hallazgo de material alóctono, de origen europeo o de la época de la conquista (Bórmida s/f). Sanguinetti de Bórmida, posteriormente menciona el hallazgo de raspadores confeccionados en vidrios, como elementos introducidos y aceptados como materia prima para talla local (Sanguinetti de Bórmida 1970). Es importante destacar que en los trabajos publicados por Bórmida y posteriormente por Sanguinetti de Bórmida no dan precisión sobre en qué margen de la laguna se realizaron los trabajos. Tampoco hacen mención a la existencia de una fortificación de principios del siglo XIX sobre las márgenes de la laguna (Figura 4).

Ahora bien, los trabajos realizados en la laguna Blanca Grande tuvieron su inicio en la década de 1960, cuando, cabe recordar, contemporáneamente se estaban realizando investigaciones históricas sobre el FBG que no solo se basaron en documentos, sino que también incorporaban el registro material de una forma no sistemática, por medio de la recolección de artefactos arqueológicos en el cementerio de la fortificación (Arena et al. 1967). Cuesta pensar que investigadores como Bórmida, desconocieran la historia y el punto donde se ubicaba el FBG. Lo mismo podemos considerar para los historiadores locales, como Arena, Cortes y Valverde, quienes estudiaron la estructura edilicia del FBG, y es improbable que ignoraran los trabajos de campo y las interpretaciones que Bórmida estaba haciendo sobre las sociedades prehistóricas que ocuparon la zona.

Para entender esta situación se debe recordar que las investigaciones históricas se efectuaban de manera paralela a los estudios arqueológicos, como si los pueblos originarios que interactuaron con los eurocriollos en el FBG fuesen distintos de los que se asentaron o realizaron actividades en el borde suroeste de la laguna. A esto debemos agregar, como se mencionó anteriormente, que los historiadores académicos no se interesaron en los conflictos y la vida cotidiana en la frontera interior durante el desarrollo de la formación del estado nacional, dejando su interpretación en mano de aquellos que se interesaran en las historias locales, usualmente estudiosos amateurs. En muchos casos, en vez de interactuar, los historiadores no se involucraban con lo arqueológico y los arqueólogos buscaban explicar los orígenes y la variación a través del tiempo de las tecnologías de los cazadores recolectores (primeros pobladores del área interserrana), sin preocuparse por el registro arqueológico postcontacto.

\section{Los trabajos de campo recientes}

En mayo de 2018, la provincia de Buenos Aires sufrió una sequía que generó que el nivel de la laguna Blanca Grande descendiera un metro por debajo de su nivel normal. Esta situación dejó al descubierto las playas del suroeste, donde se pudo detectar la presencia de diferentes materiales arqueológicos (Figuras 5 y 6).

Dada esta circunstancia, se procedió a realizar prospecciones del terreno mediante el trazado de transectas, registrando los hallazgos superficiales con GPS. Entre estos se pudo recuperar un gran número de unidades anatómicas de Equus $f$. caballus, y en menor proporción restos de Bos p. taurus.

También se recuperaron una serie de artefactos líticos confeccionados sobre calcedonia y en menor proporción sobre cuarcita; restos de fragmentos de bases cónicas y picos de botellas cortados a tijera de color verde oscuro, fragmentos de gres, un botón de ropa interior confeccionados con pasta de vidrio y fragmentos de metal corroído. Entre éstos también se registró 


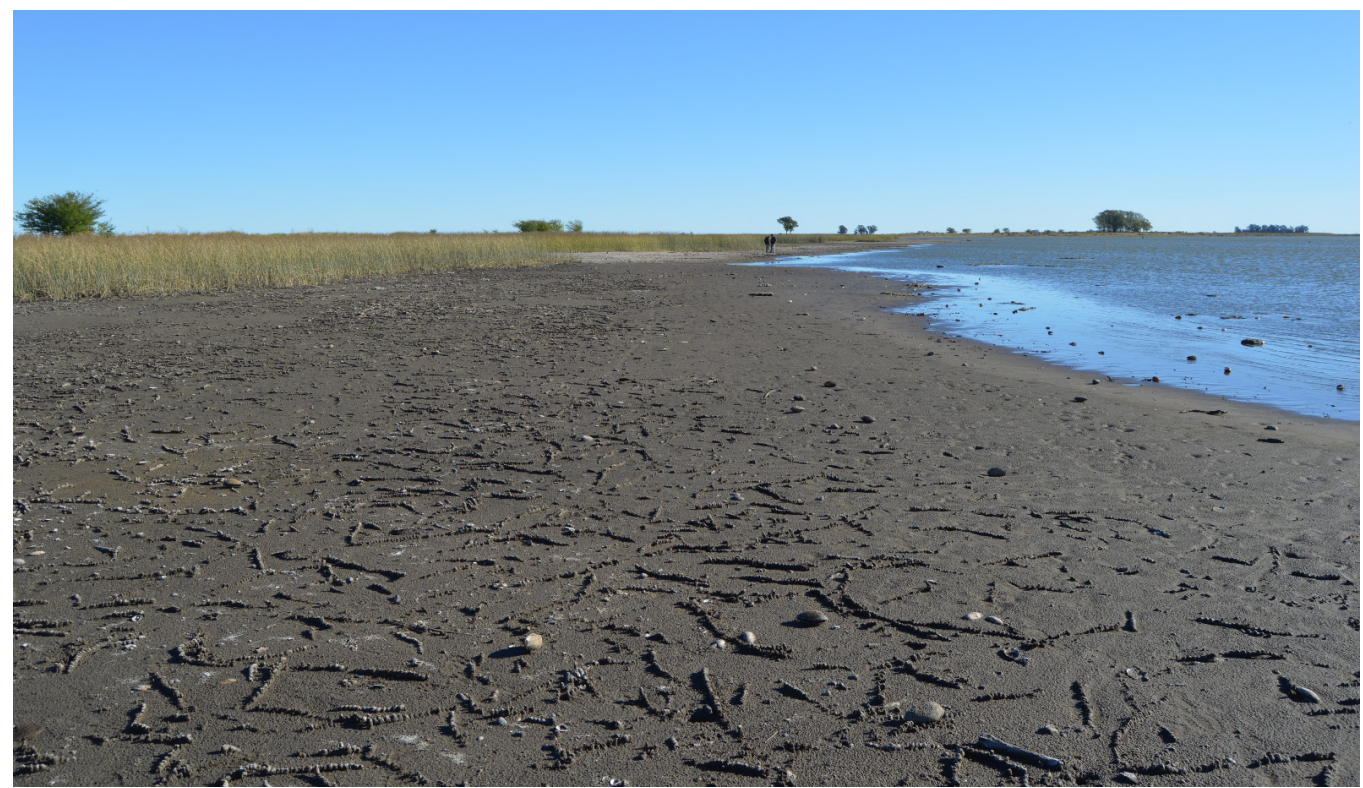

Figura 5. Playa Suroeste de la laguna Blanca Grande que limita con la parte posterior del FBG.

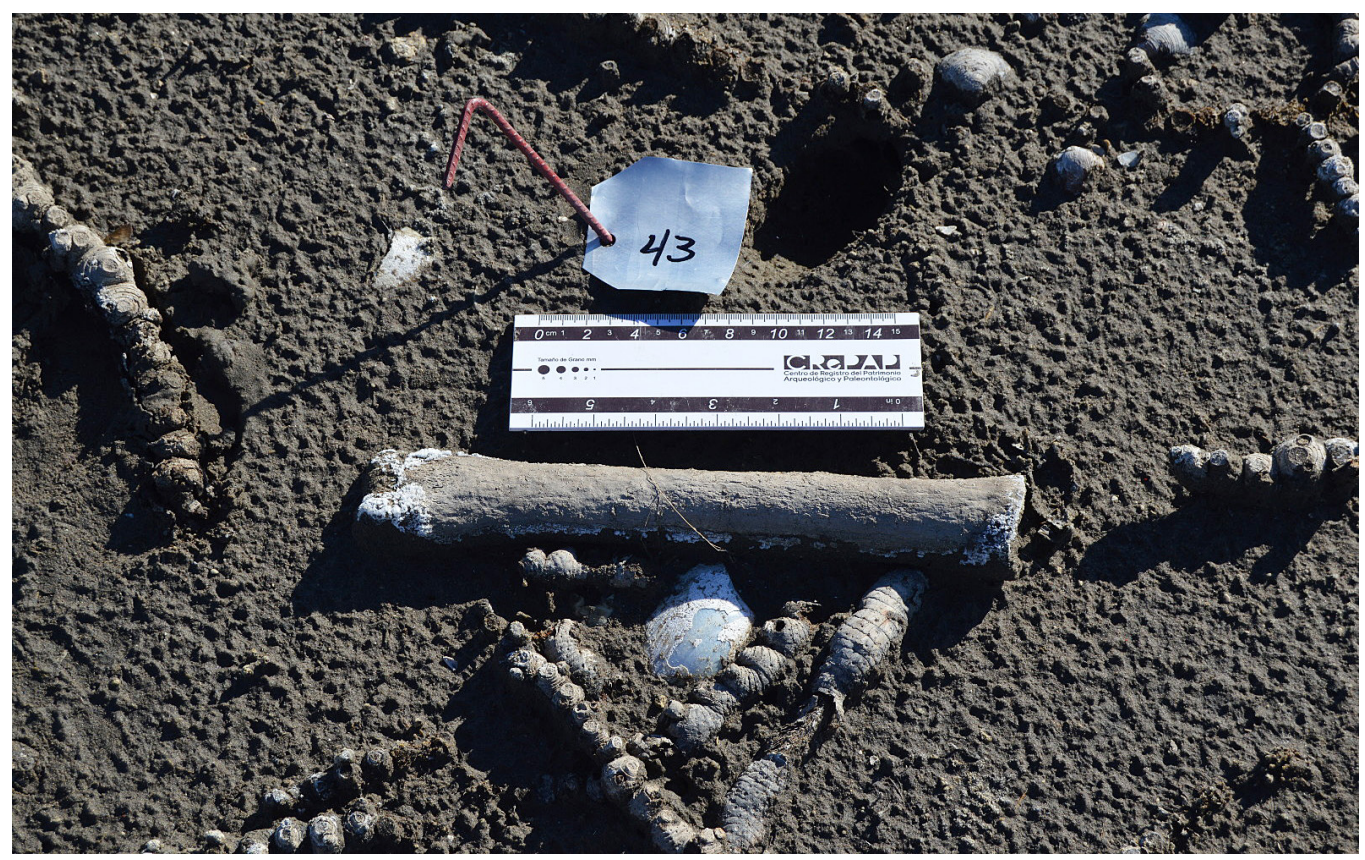

Figura 6. Prospección y rescate de los ítems arqueológicos. Se puede observar un autopodio de Equus $f$. caballus, asociado a un bivalvo Ampularis sp. semienterrado y restos de instrumentos liticos. 


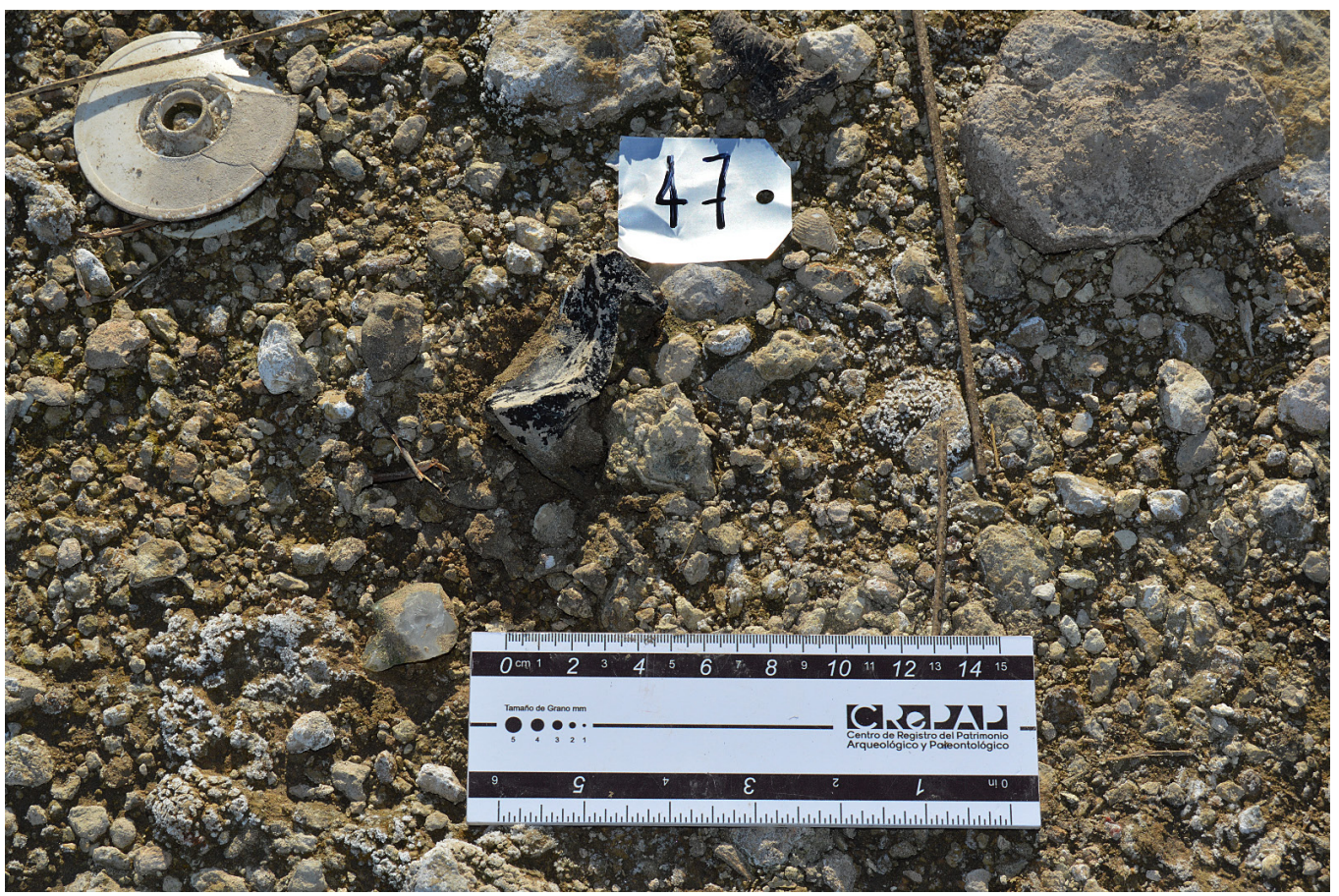

Figura 7. Registro de base de botella, junto a fragmentos líticos asociado a un carretel de tanza producto de la pesca que se practica en la actualidad. También se pueden observar los clastos de diferentes tamaños que se depositan en la parte superior de la costa.

la presencia de plomadas y lineas de tanza actuales, utilizada por pescadores de la laguna y una abundante concentración de bivalvos Ampularis sp., expuestos por el descenso abrupto de la laguna, algunos de los cuales conservaban restos orgánicos del individuo (Figura 7).

Estos materiales se encontraban sobre la superficie de la base de tosca que contiene la laguna, rodeado por un sedimento de greda y clastos de diferentes tamaños, que no llegaba a cubrirlos. Todos los materiales registrados en la playa de la laguna se encuentran ubicados en la parte posterior del FBG. Es importante resaltar que la dinámica de la laguna (oleaje, crecidas y descensos) puede generar la movilización y la concentración de materiales; la baja densidad de sedimento no permite efectuar excavaciones en el sector. Este tipo de hallazgos, dio a pensar acerca de dónde fueron efectuadas las excavaciones y prospecciones mencionadas por Bórmida (1960) y posteriormente reinterpretadas por Sanguinetti de Bórmida (1970). Se recorrió el resto de las barrancas del espejo de agua y no se registró la presencia de este tipo de materiales. Esto nos podría estar dando indicios que los trabajos efectuados por Bórmida fueron realizados en la parte posterior del FBG, a pesar que la fortificación nunca fue mencionada. Todos los materiales recuperados se encuentran en el laboratorio para ser analizados en detalle y poder determinar huellas de corte sobre las unidades anatómicas recuperadas o ver el uso de los fragmentos de vidrio como instrumentos. 
Merlo J. F. y Merlo L. - "Las investigaciones en el Fuerte Blanca Grande"

\section{Consideraciones finales}

El desarrollo de la arqueología de momentos históricos que cobró fuerte impulso en la década de 1990, se profundizó a partir del 2000, cuando se comenzaron a incorporar los registros de viajeros y cronistas de la época a los estudios arqueológicos y se produjo el incremento de investigadores que se abocaron a esta problemática, a la vez que se descubrieron nuevos sitios. Todo esto reafirmó la continuidad de los pueblos originarios en momentos históricos y la necesidad de entender cómo fueron interactuando con la oleada de diferentes colonos que se incorporaban al interior de la Provincia de Buenos Aires. También comenzó a prestarse atención a los hallazgos de artefactos tallados con técnicas locales reutilizando materias primas provenientes de Europa, como los raspadores confeccionados en vidrios recuperados en la Localidad Arqueológica El Perdido y Fuerte Lavalle (Merlo 2014) o los artefactos en vidrio recuperados en excavaciones realizadas en el Fortín Miñana (Gómez Romero 2007) y también en Arroyo Nievas 2 (Pedrotta 2005, Pedrotta y Bagaloni 2007). Este tipo de hallazgos aportan mayor evidencia a la interacción e intercambio entre los inmigrantes europeos, criollos no dueños de la tierra y las comunidades originarias.

En el caso del FBG aún no se han encontrado artefactos tallados en vidrio, pero los materiales evidencian la convivencia e intercambio (pacifico o no) entre ambas sociedades. La recuperación de una gran concentración de huesos (principalmente autopodios de Equus $f$. caballus) e instrumentos líticos, junto con elementos alóctonos de origen europeo (e.g. botones, fragmentos de botellas de vidrios) en el sector posterior del FBG aportan datos acerca de la interacción entre los diferentes grupos. También es importante tener en cuenta los procesos postdepositacionales, pero no atribuir solamente a éstos la generación de la cultura material.

En agenda futura se analizarán los ítems recuperados en los últimos trabajos para efectuar interpretaciones más ajustadas sobre el procesamiento y uso de los instrumentos líticos, el vidrio, y los elementos óseos recuperados en el sector noroeste de la fortificación y el borde la laguna Blanca Grande.

\section{Agradecimientos}

UE-INCUAPA-CONICET, dirigido por el Dr. G. Politis y Lic. J. L. Prado, a la Facultad de Ciencias Sociales de Olavarria (UNICEN), a la Comisión de Pesca Club Blanca Grande de Olavarría y a la Lic. Diana Sandra Tamburini por su colaboración y paciencia.

\section{Bibliografia}

ARENA, J.; J.H. CORTÉS Y A. VALVERDE. 1967. Ensayo Histórico del Partido de Olavarría. Municipalidad de Olavarría, Provincia de Buenos Aires.

BÁRCENA, J.R. y SCHÁVELZON. 1990. El Cabildo de Mendoza Arqueología e historia para su recuperación. Xama, pp:9-174.

BÓRMIDA, M. Sin fecha. Prolegómenos para una arqueología de la Pampa Bonaerense. Edición oficial de la Provincia de Buenos Aires. Dirección de Bibliotecas, Museos y Archivos Históricos. La Plata.

BÓRMIDA, M. 1960. Investigaciones Paleontológicas en la Región de Bolivar (Provincia de Buenos Aires). Anales de la Comisión de Investigaciones Cientificas, La Plata I:198-238.

BOSCHIN, M.T. 1991-1992. Historia de las investigaciones arqueológicas en pampa y Patagonia. Runa XX:111-144.

BOTANA, N. 1977. El Orden Conservador. Editorial Sudamericana, Buenos Aires. 
BRITTEZ, F. 2000. La comida y las cosas: una visión arqueológica de la campaña bonaerense de la segunda mitad del siglo XIX. En Vivir en la frontera: la casa, la dieta, la Pulpería, la escuela (17701870), editado por C. Mayo, pp. 169199. Editorial Biblos, Buenos Aires.

BRITTEZ, F.R. 2009. Zooarqueología, tafonomía y procesos de formación de sitios rurales pampeanos: estado de la cuestión y expectativas para momentos tardíos. Revista de Arqueología Histórica Argentina y Latinoamericana 3:47-68.

BRITTEZ, F.R. y M.I. WIBAUX. 2011. Investigaciones preliminaresen el sitio "Estancia Ballenera Vieja", un asentamiento de frontera del sudeste bonaerense. En Temas y problemas de la Arqueología Histórica, Tomo I, editado por M. Ramos, A. Tapia, F. Boganni, M. Fernández, V. Helfer, C. Landa, M. Lanza, E. Montanari, E. Néspolo y V. Pineau, pp. 361-367. Programa de Arqueología Histórica y Estudios Pluridisciplinarios, Departamento de Ciencias Sociales, Universidad Nacional de Lujan, Luján

CASANUEVA, M.L. 2004. Emprendimientos comerciales durante el siglo XIX y su incidencia en la vida de frontera (Partido de General Lavalle, Provincia de Buenos Aires). En $9^{\circ}$ Encuentro de Historia y de Arqueologia Post-conquista de los pueblos al sur del Salado, editado por J.W. Wally, M.C. Langiano, J.F. Merlo y M.N. Álvarez, pp. 107-109. Comisión Municipal de Estudios Históricos y de Arqueología Histórica, y Editorial MC, Olavarría.

CASHDAN, E. 1990 Risk and Uncertainty in Tribal and Peasant Economies. Westview Press, Boulder.
GÓMEZ ROMERO, F. 1997. Arqueología histórica en sitios militares de campaña: el caso del fortín Miñana. En Arqueología Uruguaya al Fin del Milenio. Actas del IX Congreso Nacional de Arqueología de Uruguay, Tomo II, pp. 6574. Colonia del Sacramento, Uruguay.

GÓMEZ ROMERO, F. 2007 Se presume culpable: Una arqueología de gauchos, fortines y tecnologias de poder en las Pampas Argentinas del siglo XIX. Editorial De los cuatro vientos, Buenos Aires. GÓMEZ ROMERO, F. y M. RAMOS. 1994. Miñana's Fortlet Historical Archaeology Research. Historical Archaeology in Latin America 2:15-30.

GOÑI, R. y P. MADRID.1998. Arqueología sin hornear: sitios arqueológicos históricos y el Fuerte Blanca Grande. Intersecciones 2:69-84.

LANDA, C.; E. MONTANARI y F. GÓMEZ ROMERO. 2011. Arqueología de campos de batalla: "La Verde", primeras aproximaciones (Partido de 25 de Mayo, Provincia de Buenos Aires). En Temas y problemas de la Arqueología Histórica. Tomo I, editado por M. Ramos, A. Tapia, F. Boganni, M. Fernández, V. Helfer, C. Landa, M. Lanza, E. Montanari, E. Néspolo y V. Pineau, pp. 137-144. Programa de Arqueología Histórica y Estudios Pluridisciplinarios, Departamento de Ciencias Sociales. Universidad Nacional de Luján, Luján.

LANGIANO, M. del C. 2007. Análisis comparativo de conjuntos de gres recuperados en fuertes y fortines del siglo XIX. En Arqueología de las Pampas.Tomo II, editado por C. Bayón, A. Pupio, M.I. González, N. Flegenheimer y M. Freire, pp. 845-857. Sociedad Argentina de Antropología, Buenos Aires.

LANGIANO, M. del C. y J.F. MERLO. 2013. "Camino de los Indios a Salinas". Arqueología y paisaje en Frontera Sur (provincia de Buenos Aires 1850-1880). Anuario de Arqueología (UNR) 5:169- 
Merlo J. F. y Merlo L. - "Las investigaciones en el Fuerte Blanca Grande"

188.

LANGIANO, M. del C.; J.F. MERLO y P. ORMAZABAL. 1997. Arqueología de puestos fortificados en el camino a Salinas. En Actas de las primeras jornadas regionales de historia y arqueología del siglo XIX, pp. 12-18. Tapalqué.

LANGIANO, M. del C.; J.F. MERLO y P. ORMAZABAL. 2002. Relevamiento de Fuertes y Fortines, con relación al Camino de los Indios a Salinas. En Del Mar a los Salitrales. Diez mil años de Historia Pampeana en el Umbral del Tercer Milenio, editado por D. Mazanti, M. Berón y F. Oliva, pp. 53-64. Sociedad Argentina de Antropología y Laboratorio de Arqueología, Facultad de Humanidades. Universidad Nacional de Mar del Plata, Mar del Plata.

LANGIANO, M. del C.; J.F. MERLO y P. ORMAZABAL. 2006. Presencia de artefactos líticos en fuertes y fortines en el Camino de los Indios a Salinas Grandes. Provincia de Buenos Aires (siglo XIX). En Actas IV Congreso de Arqueología en Colombia. Transdisciplina, Multiculturalidad y Gestión Patrimonial, pp. 114. Universidad Tecnológica de Pereira, Pereira, Colombia.

LANGIANO, M. del C.; J.F. MERLO y P. ORMAZABAL. 2009. Ocupación diferencial del paisaje en torno al Camino de los indios a Salinas (Provincia de Buenos Aires). En Actas del XV Congreso Nacional de Arqueología, Tomo III, pp. 441448. Río Cuarto, Córdoba.

LEONI, J.B.; D. TAMBURINI; T. ACEDO y G. SCARAFIA. 2006. Arqueología del Fuerte General Paz (Partido de Carlos Casares, Provincia de Buenos Aires), comandancia de la Frontera Oeste (1869-1876). Revista de la Escuela de Antropologia (UNR) XII:149-162.

LEONI, J.B.; D. TAMBURINI; T. ACEDO y G. SCARAFIA. 2007. De balas perdidas y vidrios rotos: distribución espacial de artefactos superficiales en el Fuerte
General Paz (1869-1876). Revista de Arqueología Histórica Argentina y Latinoamericana 1:29-64.

LEONI, J.B.; D. TAMBURINI; T. ACEDO y G. SCARAFIA. 2008a. El Fuerte General Paz y el Fortín Algarrobos: Arqueología de emplazamientos militares en la Frontera Oeste de Buenos Aires (18691876). Revista de la Escuela de Antropologia (UNR) XIV:45-58.

LEONI, J.B.; D. TAMBURINI; T. ACEDO y G. SCARAFIA. 2008b. Arqueologia del Fuerte General Paz: datos históricos, registro arqueológico y potencial interpretativo. En $10^{\circ}$ Encuentro de Historia y de Arqueología Post-conquista de los pueblos al sur del Salado, editado por J.W. Wally, M.C. Langiano, J.F. Merlo y M. Álvarez,pp. 119-149. Comisión Municipal de Estudios Históricos y de Arqueología Histórica, Olavarría.

LEONI, J.B.; D. TAMBURINI; T. ACEDO y G. SCARAFIA. 2010. Proyecto Arqueológico Fuerte General Paz, comandancia de la Frontera Oeste de la Provincia de Buenos Aires entre 1869 y 1877. Anuario de Arqueología (UNR) 2:217-230.

MADRID, P. 1991. Infraestructura indigena para el mantenimiento y traslado de ganado introducido: el caso del Sistema Serrano de Pillahuinco, provincia de Buenos Aires. Boletín del Centro 3:6571.

MANDRINI, R. 2007. La historigrafia argentina, los pueblos originarios y la incomodidad de los historiadores. Quinto Sol (Instituto de Estudios Socio-Históricos. Facultad de Ciencias Humanas de La Pampa) 11:19-38.

MENGHIN, O. y M. BÓRMIDA.1950. Investigaciones prehistóricas en cuevas de Tandil (Provincia de Buenos Aires). Runa III(1-2):1-36.

MERLO, J.F. 1999. Estudio de los Recursos Faunisticos en el Fuerte Blanca Grande Provincia de Buenos Aires. Tesis de grado, UNICEN, Ola- 
varría.

MERLO, J.F. 2003. Análisis preliminares de fauna en sitios fortificados del área interserrana (Provincia de Buenos Aires). En Actas del I Congreso Nacional de Arqueologia Histórica, pp. 813-820. Corregidor, Buenos Aires.

MERLO, J.F. 2004. El uso de los recursos faunísticos en la dieta de los habitantes del Fortín El Perdido, Olavarria. Provincia de Buenos Aires. En $9^{\circ}$ Encuentro de Historia $y$ de Arqueología Post-conquista de los pueblos al sur del Salado, editado por J.W. Wally, M.C. Langiano, J.F. Merlo y M.N. Álvarez,pp. 173-183. Comisión Municipal de Estudios Históricos y de Arqueología Histórica y Editorial MC, Olavarría.

MERLO, J.F. 2007. Avances sobre el uso de recursos faunísticos en la dieta de los habitantes de puestos fortificados en el Camino a Salinas (área interserrana bonaerense. Intersecciones en Antropología 8:185196.

MERLO, J. F. 2014. Aprovechamiento de recursos faunísticos en sitios fortificados de la frontera sur bonaerense en el siglo XIX. Tesis doctoral, UNICEN, Olavarría.

MERLO, J.F. y N. MORO. 2004. La Utilización de instrumental indígena en El Fortín El Perdido. En $9^{\circ}$ Encuentro de Historia y de Arqueología Post-conquista de los pueblos al sur del Salado, editado por J.W. Wally, M.C. Langiano, J.F. Merlo y M.N. Álvarez, pp.184-192. Comisión Municipal de Estudios Históricos y de Arqueología Histórica y
Editorial MC, Olavarría

MUGUETA, M. y M. GUERCI. 1997. El cantón Tapalqué viejo y la cultura de Fronteras: La permanencia de los pobladores en las adyacencias de los fortines. En Actas de las primeras jornadas de historia y Arqueología del Siglo XIX, pp. 33-40. Tapalqué.

PALADINO, C. 1994. Tenemeche. Situación Histórica de la Blanca Grande. Club de Pescadores Ciudad de Olavarría, Olavarría.

PEDROTTA, V. 2005. Las sociedades indigenas de la Provincia de Buenos Aires entre los siglos XVI y XIX. Tesis doctoral, Facultad de Ciencias Naturales, Universidad Nacional de La Plata, La Plata.

PEDROTTA, V. y V. BAGALONI. 2005. Looking at interethnic relations in the Southern Border through glass remains: the nineteenth-century Pampa region, Argentina. International Journal of Historical Archaeology 9 (3):177-193.

PEDROTTA, V. y V. BAGALONI. 2007. Bebidas, comidas, remedios y "vicios". Las prácticas de uso y descarte de recipientes de vidrio por los indios amigos de la frontera sur (siglo XIX). En Arqueología en las Pampas.Tomo II, editado por C. Bayón, A. Pupio, M.I. González, N. Flegenheimer y M. Freire, pp. 815-834. Sociedad Argentina de Antropología, Buenos Aires.

PEDROTTA, V. y V. BAGALONI. 2011. Resultados preliminares del análisis de los materiales vítreos del sitio Arroyo Nievas 2 (Olavarría, Provincia de Buenos Aires). En Estudio de Arqueología Histórica, Investigaciones argentinas pluridisciplinarias, editado por A. Tapia, M. Ramos y C. Baldassarre, pp. 97108. Editorial Caracol, Buenos Aires.

PEDROTTA, V y F. GÓMEZ ROMERO. 1997. El rol de los datos escritos en investigaciones de arqueología histórica. En Actas de las Primeras Jornadas 
Merlo J. F. y Merlo L. - "Las investigaciones en el Fuerte Blanca Grande"

Regionales de Historia y Arqueología del Siglo XIX, pp. 41-50. Facultad de Ciencias Sociales, UNICEN, Olavarría y Municipalidad de Tapalqué, Tapalqué.

PEDROTTA, V.; V. BAGALONI y L. DUGUINE. 2011. Análisis químicos aplicados a las investigaciones arqueológicas de las construcciones de piedras del sistema de Tandil. En Estudio de Arqueología Histórica. Investigaciones argentinas pluridisciplinarias. Tomo I, editado por A. Tapia, M. Ramos y C. Baldassarre, pp. 389-404. Editorial Caracol, Buenos Aires.

RAMOS, M.; V. HELFER; M. LANZA; A. ROMELLI; N.TRENCH y R. SENESI. 2008. La casa de Florentino Ameghino en Luján. Estudios de detección, Arqueológicos y Documentales. En Continuidad y Cambio Cultural en Arqueología Histórica, editado por M.T. Carrara,pp. 150159. Escuela de Antropología, Facultad de Humanidades y Artes, Universidad Nacional de Rosario, Rosario.

RAPOPORT, M. 2000. Historia Económica, politica y social de la Argentina (18802000). Editorial Macchi, Buenos Aires.

SANGUINETTI DE BÓRMIDA, A. 1970. La neolitización de las áreas marginales de la América del Sur. Relaciones de la Sociedad Argentina de Antropología $\mathrm{V}(1)$ :9-23.

SEMPÉ, C.; B. BALESTA; C. PALEO; M. PÉREZ MERONI y N. ZAGORODNY. 1991. Algunas precisiones sobre el desarrollo histórico-cultural indigena en la cuenca deprimida de la Pampa Húmeda. En Actas de las Jornadas Chivilcoyanas en Ciencias Sociales y Naturales, pp. 219223. Chivilcoy, Buenos Aires.

SILVEIRA, M.J. 1992. Etnohistoria y arqueología en la pampa interserrana (Provincia de Buenos Aires). Palimpsesto $2: 29-50$.

SILVEIRA, M.J. 1995. Casa Peña: análisis de restos óseos. En Actas Segunda Conferenca Internacional De Arqueolo- gia Historica Americana, pp. 75-90. The University of South Carolina, Columbia, South Carolina. 
